\title{
Avaliação da hidrólise da lactose por $\beta$-galactosidase comercial em leite UHT
}

\author{
Evaluation of lactose hydrolysis by commercial $\beta$-galactosidase in UHT millk \\ Evaluación de la hidrolisis de lactosa por $\beta$-galactosidasa comercial en leche UHT
}

Recebido: 16/10/2021 | Revisado: 26/10/2021 | Aceito: 30/10/2021 | Publicado: 01/11/2021

\author{
Lainy Waleska de Brito Sodré \\ ORCID: https://orcid.org/0000-0002-6120-1813 \\ Universidade do Estado de Mato Grosso, Brasil \\ E-mail: lainy.brito@hotmail.com \\ Celina Martins Decol \\ ORCID: https://orcid.org/0000-0003-3991-374X \\ Universidade do Estado de Mato Grosso, Brasil \\ E-mail: celinadecol@unemat.br
}

\begin{abstract}
Resumo
O leite é um alimento consumido amplamente por pessoas de todas as faixas etárias, em razão de fornecer cálcio e proteína para a dieta humana. Com o aumento do número de pessoas com deficiência da enzima lactase, que ocasiona distúrbios gastrointestinais após o consumo de leite e seus derivados, diversas são as inovações que facilitam a alimentação das pessoas que possuem intolerância. De tal maneira, a enzima lactase de origem microbiana tem sido a mais indicada e única autorizada para o uso em processos alimentícios para a hidrólise da lactose. O objetivo deste estudo foi avaliar a hidrólise da lactose presente em leite fluido semidesnatado em intervalos de 5 minutos até o tempo final de 60 minutos. Foram realizados dois ensaios distintos sobre a atividade da enzima $\beta$-galactosidase: a) usando enzima lactase comercial produzida por Aspergillus orizae e b) usando preparado enzimático contendo lactase de origem microbiana (A. orizae), protease e lipase. A composição do leite foi avaliada utilizando o equipamento Master Mini ${ }^{\circledR}$ com princípio de funcionamento por ultrassom. A hidrólise provocou alterações em algumas características físico-quimicas do leite, aumento da densidade, sólidos não gordurosos, proteínas, minerais e redução do ponto de congelamento. As duas enzimas mostraram resultados diferentes, visto que uma delas proporcionou maior redução que a outra, entretanto não se alcançou $90 \%$. O valor encontrado no presente estudo foi significativamente inferior ao esperado para um produto voltado aos indivíduos intolerantes a lactose.
\end{abstract}

Palavras-chave: Lactase; Hidrólise enzimática; Redução.

\begin{abstract}
Milk is a food widely consumed by people of all age groups, because it provides calcium and protein for the human diet. With the increase in the number of people with a deficiency of the enzyme lactase, which causes gastrointestinal disorders after the consumption of milk and its derivatives, there are several innovations that facilitate the feeding of people with intolerance. Thus, the enzyme lactase of microbial origin has been the most indicated and only authorized for use in food processes for the hydrolysis of lactose. The objective of this study was to evaluate the hydrolysis of lactose present in semi-skimmed fluid milk at intervals of 5 minutes until the final time of 60 minutes. Two different assays were performed on the activity of the $\beta$-galactosidase enzyme: a) using commercial enzyme lactase produced by Aspergillus orizae and b) using enzymatic preparation containing lactase of microbial origin (A. orizae), protease and lipase. The composition of the milk was evaluated using the Master Mini $®$ equipment with ultrasonic operation principle. The hydrolysis caused changes in some physical-chemical characteristics of milk, increased density, nongreasy solids, proteins, minerals and freezing point reduction. The two enzymes showed different results, since one of them provided a greater reduction than the other one, but did not reach $90 \%$. The value found in the present study was significantly lower than expected for a product targeted to lactose intolerant individuals.
\end{abstract}

Keywords: Lactase; Enzymatic hydrolysis; Reduction.

\section{Resumen}

La leche es un alimento muy consumido por personas de todas las edades, ya que aporta calcio y proteínas para la dieta humana. Con el aumento del número de personas con deficiencia de la enzima lactasa, que provoca trastornos gastrointestinales tras el consumo de leche y sus derivados, existen varias innovaciones que facilitan la alimentación de personas con intolerancia. Así, la enzima lactasa de origen microbiano ha sido la más indicada y la única autorizada para su uso en procesos alimentarios para la hidrólisis de lactosa. El objetivo de este estudio fue evaluar la hidrólisis de lactosa presente en la leche líquida semidesnatada a intervalos de 5 minutos hasta un tiempo final de 60 minutos. Se realizaron dos ensayos diferentes sobre la actividad de la enzima $\beta$-galactosidasa: a) usando enzima lactasa comercial producida por Aspergillus orizae yb) usando una preparación enzimática que contiene lactasa de origen microbiano (A. orizae), proteasa y lipasa. La composición de la leche se evaluó utilizando el equipo Master 
Mini ® con un principio de funcionamiento ultrasónico. La hidrólisis provocó cambios en algunas características fisicoquímicas de la leche, aumento de la densidad, sólidos no grasos, proteínas, minerales y reducción del punto de congelación. Las dos enzimas mostraron resultados diferentes, ya que una de ellas brindó mayor reducción que la otra, sin embargo no se alcanzó el $90 \%$. El valor encontrado en este estudio fue significativamente más bajo de lo esperado para un producto dirigido a personas intolerantes a la lactosa.

Palabras clave: Lactasa; Hidrólisis encimática; Reducción.

\section{Introdução}

O leite é um alimento rico em nutrientes de fácil absorção e elevada digestibilidade (Amancio, 2015). É considerado fonte importante de cálcio e proteína na dieta humana, sendo recomendado para todas as faixas etárias. Sua composição inclui proteínas, gorduras, vitaminas, sais e a lactose, um dissacarídeo exclusivo do leite formado por monômeros de glicose e galactose, não sendo absorvida na forma composta, é hidrolisada no intestino delgado pela enzima $\beta$-galactosidase (lactase) (Ferreira et al., 2016).

Como mamíferos, os seres humanos nascem com elevada atividade de lactase endógena, porém a tendência é a diminuição desta atividade após o desmame, estabilizando entre os cinco e dez anos de idade. No Brasil, mais de $60 \%$ da população apresenta baixo índice de absorção de lactose, decorrente da deficiência da enzima lactase, o que ocasiona distúrbios gastrointestinais após o consumo de leite e seus derivados (Da Silva Campos et al., 2015).

$\mathrm{O}$ uso de $\beta$-galactosidase tem sido amplamente estudado como uma forma de hidrolisar a lactose em seus monômeros glicose e galactose, proporcionando a produção de alimentos que atendam a um público que corresponde a cerca de $60 \%$ da população brasileira: aqueles indivíduos que apresentam, em qualquer grau, incapacidade de produzir a $\beta$ galactosidase endógena (Ferreira et al., 2016). Essas enzimas são obtidas através de micro-organismos, conforme preconizado pela RDC No 54, de 7 de outubro de 2014 (BRASIL, 2014).

A indústria apresenta constantemente uma ampla gama de produtos considerados "zero lactose", ou seja, que apresentam 90\% ou mais de hidrólise do açúcar. No entanto, sua disponibilidade ao consumidor final ainda é muito heterogênea ou ainda o seu elevado custo dificulta a aquisição dos mesmos. Uma alternativa é o uso de complexos enzimáticos contendo $\beta$ galactosidase destinados ao preparo de alimentos em pequena escala, no entanto, a falta de ensaios científicos sobre os mesmos, bem como as instruções pouco precisas dos fabricantes tem se mostrado um obstáculo ao uso (Araújo, 2015).

Dessa maneira, foi proposta a avaliação da atividade de $\beta$-galactosidase em leite fluido UHT (do inglês Ultra Hight Temperature) semidesnatado ao longo de 60 minutos e verificar se a hidrólise se mostrará eficaz.

\section{Metodologia}

\subsection{Local do experimento}

Os ensaios experimentais foram conduzidos nas dependências do Campus Universitário Deputado Estadual Renê Barbour, da UNEMAT, localizado na cidade de Barra do Bugres - MT. As análises foram realizadas no Laboratório de Química.

\subsection{Ensaios sobre a atividade da $\beta$-galactosidase}

Foram realizados dois ensaios distintos sobre a atividade da enzima $\beta$-galactosidase: a) usando enzima lactase comercial produzida por Aspergillus orizae e b) usando preparado enzimático contendo lactase de origem microbiana (A. orizae), protease e lipase. Ambos os experimentos foram conduzidos num período de 60 minutos, com cada análise realizada em intervalos de 5 minutos. 


\subsubsection{Enzima $\beta$-galactosidase}

A hidrólise da lactose foi realizada utilizando a Lactase ( $\beta$-galactosidase) comercial produzida por Aspergillus oryzae com 51,5mg/g de pó e com Preparado enzimático a base de lactase ( $\beta$-galactosidase) produzida por Aspergillus oryzae, na concentração de $51,5 \mathrm{mg} / \mathrm{g}$, lipase $(1,5 \mathrm{mg} / \mathrm{g})$ produzida por Candida rugosa e protease $(46 \mathrm{mg} / \mathrm{g})$ originária de $A$ niger e $A$ oryzae. As enzimas foram utilizadas conforme as instruções do fabricante, indicado na Figura 1.

Figura 1 - Etapas indicadas pelos fabricantes para utilização das enzimas.

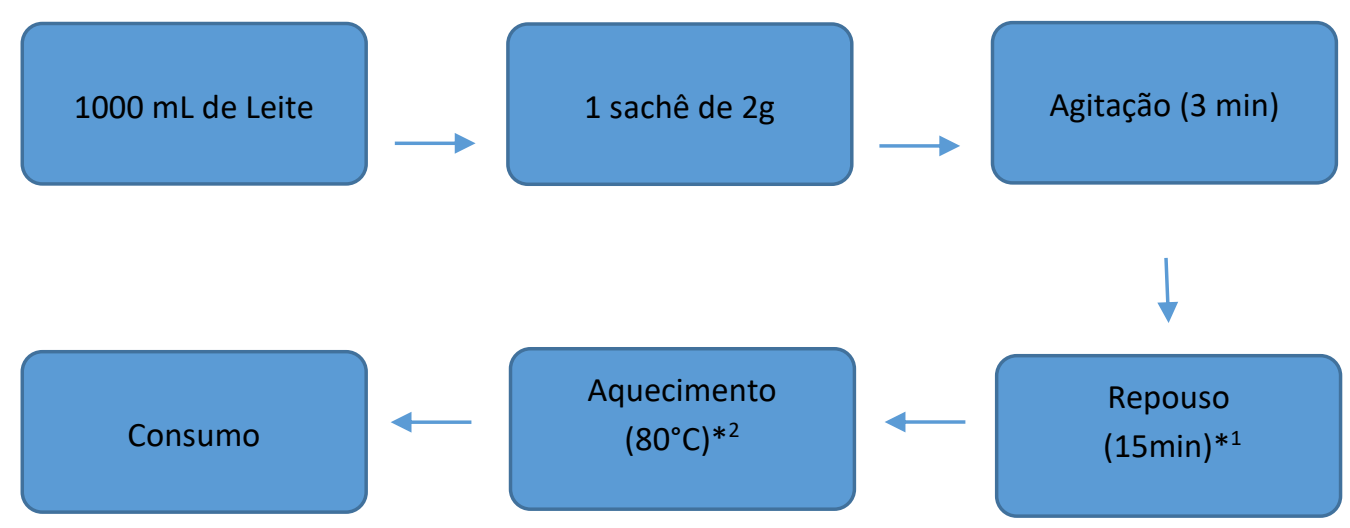

Fonte: Elaboração própria das autoras (2018).

\subsubsection{Determinação da composição do leite}

A composição do leite foi avaliada utilizando o equipamento Master Mini ${ }^{\circledR}$, que utiliza da tecnologia de ultrassom descrita por Venturoso et al. (2007) da seguinte forma: inicialmente aquecendo as amostras a $80^{\circ} \mathrm{C}$, provocando agitação dos sólidos presentes no líquido e aumentando a frequência do som, enquanto a gordura, solubilizada pelo aquecimento, diminui a velocidade do som.

\subsubsection{Atividade de $\beta$-galactosidase em leite fluido}

Nos ensaios em leite fluido, a atividade da enzima foi avaliada com base no abaixamento do ponto de congelamento pela ação da enzima $\beta$-galactosidase sobre a lactose com produção de monossacarídeos, conforme consta no informe técnico do fabricante da enzima (Prozyn, 2007) e respaldado por diversos estudos com o mesmo fim (Cunha Et Al., 2007; Klein Et Al., 2010; Santos Et Al., 2019; Ceroni; Vanin, 2021). O Grau de Hidrólise (GH\%), para cada tempo de reação, foi calculado utilizando a Equação 1.

$$
G H=\left(350,877 \times \text { Crioscopia final }^{\circ} \mathrm{H}\right)-\left(\frac{\text { Crioscopia inicial }^{\circ} \mathrm{H}}{0,00285}\right)
$$

Os dados foram computados em planilha eletrônica e submetidos à ANOVA, teste de Tukey a 5\% para verificar se há diferença estatística entre as médias, e Análise de Regressão para determinar os modelos de redução de lactose pela enzima lactase.

*1 Para a verificação da atividade enzimática, o repouso para atuação do produto, neste experimento, variou de 0 a 60 minutos.

*2 $\mathrm{O}$ equipamento Master Mini ${ }^{\circledR}$ já aquece a amostra a $80^{\circ} \mathrm{C}$, desta forma, esta etapa foi realizada no próprio analisador eletrônico do leite. 


\section{Resultados e Discussão}

Para uma melhor compreensão da eficiência das duas marcas de lactase avaliadas, o presente estudo irá, inicialmente, apresentar os dados completos obtidos para as amostras de leite semidesnatado UHT submetidas à hidrólise de lactose pela enzima Lactase (A) e Preparado Enzimático contendo Lactase (B).

\subsection{Leite UHT com adição da enzima A e B}

Os parâmetros físico-químicos e de composição das amostras de leite semidesnatado UHT submetidos à hidrólise de lactose pela enzima lactase comercial (A) e preparado enzimático contendo lactase (B) estão dispostos nas Tabelas 1 e 2 , respectivamente.

Tabela 1 - Parâmetros físico químicos do leite semidesnatado UHT adicionado de enzima lactase comercial (A).

\begin{tabular}{|c|c|c|c|c|c|c|c|}
\hline $\begin{array}{c}\text { Tempo } \\
\text { (min) }\end{array}$ & $\begin{array}{c}\text { Gordura } \\
(\%)\end{array}$ & $\begin{array}{c}\text { SNG } \\
(\%)\end{array}$ & $\begin{array}{c}\text { Lactose } \\
\text { Estimada } \\
(\%)\end{array}$ & $\begin{array}{c}\text { Proteína } \\
(\%)\end{array}$ & $\begin{array}{c}\text { Minerais } \\
(\%)\end{array}$ & $\begin{array}{l}\text { Densidade } \\
(\mathrm{g} / \mathrm{l})\end{array}$ & $\begin{array}{c}\text { Crioscopia } \\
\left({ }^{\circ} \mathrm{H}\right)\end{array}$ \\
\hline 0 & $1,24^{\mathrm{NS}}$ & $9,49^{a}$ & $5,20^{\mathrm{b}}$ & $3,47^{\mathrm{NS}}$ & $0,77^{\mathrm{NS}}$ & $1034,56^{\mathrm{b}}$ & $-0,614^{a}$ \\
\hline 5 & $1,24^{\mathrm{NS}}$ & $9,48^{\mathrm{a}}$ & $5,19^{\mathrm{b}}$ & $3,47^{\mathrm{NS}}$ & $0,77^{\mathrm{NS}}$ & $1034,54^{\mathrm{b}}$ & $-0,614^{a}$ \\
\hline 10 & $1,25^{\mathrm{NS}}$ & $9,50^{\mathrm{a}}$ & $5,22^{\mathrm{ab}}$ & $3,48^{\mathrm{NS}}$ & $0,77^{\mathrm{NS}}$ & $1034,59^{\mathrm{ab}}$ & $-0,615^{a}$ \\
\hline 15 & $1,27^{\mathrm{NS}}$ & $9,54^{\mathrm{a}}$ & $5,31^{\mathrm{ab}}$ & $3,49^{\mathrm{NS}}$ & $0,78^{\mathrm{NS}}$ & $1034,76^{\mathrm{ab}}$ & $-0,618^{a}$ \\
\hline 20 & $1,20^{\mathrm{NS}}$ & $9,49^{\mathrm{a}}$ & $5,20^{\mathrm{b}}$ & $3,47^{\mathrm{NS}}$ & $0,77^{\mathrm{NS}}$ & $1034,61^{\mathrm{ab}}$ & $-0,614^{a}$ \\
\hline 25 & $1,27^{\mathrm{NS}}$ & $9,54^{\mathrm{a}}$ & $5,31^{\mathrm{ab}}$ & $3,49^{\mathrm{NS}}$ & $0,78^{\mathrm{NS}}$ & $1034,76^{\mathrm{ab}}$ & $-0,618^{a}$ \\
\hline 30 & $1,20^{\mathrm{NS}}$ & $9,49^{a}$ & $5,20^{\mathrm{b}}$ & $3,47^{\mathrm{NS}}$ & $0,77^{\mathrm{NS}}$ & $1034,61^{\mathrm{ab}}$ & $-0,614^{a}$ \\
\hline 35 & $1,26^{\mathrm{NS}}$ & $9,55^{\mathrm{a}}$ & $5,32^{\mathrm{ab}}$ & $3,49^{\mathrm{NS}}$ & $0,78^{\mathrm{NS}}$ & $1034,78^{\mathrm{ab}}$ & $-0,619^{a}$ \\
\hline 40 & $1,25^{\mathrm{NS}}$ & $9,54^{\mathrm{a}}$ & $5,30^{\mathrm{ab}}$ & $3,49^{\mathrm{NS}}$ & $0,78^{\mathrm{NS}}$ & $1034,77^{\mathrm{ab}}$ & $-0,618^{a}$ \\
\hline 45 & $1,26^{\mathrm{NS}}$ & $9,56^{\mathrm{a}}$ & $5,33^{\mathrm{ab}}$ & $3,49^{\mathrm{NS}}$ & $0,78^{\mathrm{NS}}$ & $1034,82^{\mathrm{ab}}$ & $-0,619^{a}$ \\
\hline 50 & $1,26^{\mathrm{NS}}$ & $9,56^{\mathrm{a}}$ & $5,34^{\mathrm{ab}}$ & $3,50^{\mathrm{NS}}$ & $0,78^{\mathrm{NS}}$ & $1034,82^{\mathrm{ab}}$ & $-0,619^{a}$ \\
\hline 55 & $1,26^{\mathrm{NS}}$ & $9,57^{\mathrm{a}}$ & $5,36^{\mathrm{ab}}$ & $3,50^{\mathrm{NS}}$ & $0,78^{\mathrm{NS}}$ & $1034,88^{\mathrm{ab}}$ & $-0,620^{a}$ \\
\hline 60 & $1,28^{\mathrm{NS}}$ & $9,60^{\mathrm{a}}$ & $5,43^{\mathrm{a}}$ & $3,52^{\mathrm{NS}}$ & $0,78^{\mathrm{NS}}$ & $1034,98^{\mathrm{a}}$ & $-0,623^{a}$ \\
\hline
\end{tabular}

Médias seguidas de mesma letra não diferem entre si ao nível de 5\% de significância pelo teste Tukey.

*NS: Não significativo pela Análise de Variância.

Fonte: Elaboração própria das autoras (2018). 
Tabela 2 - Parâmetros físico-químicos do leite semidesnatado UHT adicionado de preparado enzimático contendo lactase (B) ao longo de 60 minutos.

\begin{tabular}{cccccccc}
\hline $\begin{array}{c}\text { Tempo } \\
(\mathrm{min})\end{array}$ & $\begin{array}{c}\text { Gordura } \\
(\%)\end{array}$ & $\begin{array}{c}\text { SNG } \\
(\%)\end{array}$ & $\begin{array}{c}\text { Lactose } \\
\text { Estimada }\end{array}$ & $\begin{array}{c}\text { Proteína } \\
(\%)\end{array}$ & $\begin{array}{c}\text { Minerais } \\
(\%)\end{array}$ & $\begin{array}{c}\text { Densidade } \\
(\mathrm{g} / \mathrm{l})\end{array}$ & $\begin{array}{c}\text { Crioscopia } \\
\left({ }^{\circ} \mathrm{H}\right)\end{array}$ \\
0 & $1,47^{\mathrm{NS}}$ & $8,98^{\mathrm{b}}$ & $5,06^{\mathrm{a}}$ & $3,37^{\mathrm{a}}$ & $0,75^{\mathrm{NS}}$ & $1032,54^{\mathrm{a}}$ & $-0,580^{\mathrm{a}}$ \\
5 & $1,51^{\mathrm{NS}}$ & $9,23^{\mathrm{ab}}$ & $4,75^{\mathrm{ab}}$ & $3,34^{\mathrm{a}}$ & $0,75^{\mathrm{NS}}$ & $1033,45^{\mathrm{a}}$ & $-0,597^{\mathrm{a}}$ \\
10 & $1,40^{\mathrm{NS}}$ & $9,34^{\mathrm{a}}$ & $4,61^{\mathrm{b}}$ & $3,42^{\mathrm{a}}$ & $0,76^{\mathrm{NS}}$ & $1033,95^{\mathrm{a}}$ & $-0,605^{\mathrm{b}}$ \\
15 & $1,39^{\mathrm{NS}}$ & $9,35^{\mathrm{a}}$ & $4,60^{\mathrm{b}}$ & $3,42^{\mathrm{a}}$ & $0,76^{\mathrm{NS}}$ & $1033,99^{\mathrm{a}}$ & $-0,605^{\mathrm{b}}$ \\
20 & $1,39^{\mathrm{NS}}$ & $9,38^{\mathrm{a}}$ & $4,56^{\mathrm{b}}$ & $3,43^{\mathrm{a}}$ & $0,77^{\mathrm{NS}}$ & $1034,06^{\mathrm{a}}$ & $-0,608^{\mathrm{b}}$ \\
25 & $1,41^{\mathrm{NS}}$ & $9,41^{\mathrm{a}}$ & $4,56^{\mathrm{b}}$ & $3,43^{\mathrm{a}}$ & $0,77^{\mathrm{NS}}$ & $1034,08^{\mathrm{a}}$ & $-0,608^{\mathrm{b}}$ \\
30 & $1,41^{\mathrm{NS}}$ & $9,38^{\mathrm{a}}$ & $4,54^{\mathrm{b}}$ & $3,44^{\mathrm{a}}$ & $0,77^{\mathrm{NS}}$ & $1034,17^{\mathrm{a}}$ & $-0,609^{\mathrm{b}}$ \\
35 & $1,42^{\mathrm{NS}}$ & $9,42^{\mathrm{a}}$ & $4,50^{\mathrm{b}}$ & $3,45^{\mathrm{a}}$ & $0,77^{\mathrm{NS}}$ & $1034,25^{\mathrm{a}}$ & $-0,611^{\mathrm{b}}$ \\
40 & $1,41^{\mathrm{NS}}$ & $9,44^{\mathrm{a}}$ & $4,49^{\mathrm{b}}$ & $3,45^{\mathrm{a}}$ & $0,77^{\mathrm{NS}}$ & $1034,29^{\mathrm{a}}$ & $-0,612^{\mathrm{b}}$ \\
45 & $1,41^{\mathrm{NS}}$ & $9,45^{\mathrm{a}}$ & $4,47^{\mathrm{b}}$ & $3,46^{\mathrm{a}}$ & $0,77^{\mathrm{NS}}$ & $1034,33^{\mathrm{a}}$ & $-0,613^{\mathrm{b}}$ \\
50 & $1,42^{\mathrm{NS}}$ & $9,47^{\mathrm{a}}$ & $4,45^{\mathrm{b}}$ & $3,46^{\mathrm{a}}$ & $0,77^{\mathrm{NS}}$ & $1034,38^{\mathrm{a}}$ & $-0,614^{\mathrm{b}}$ \\
55 & $1,41^{\mathrm{NS}}$ & $9,48^{\mathrm{a}}$ & $4,43^{\mathrm{b}}$ & $3,47^{\mathrm{a}}$ & $0,78^{\mathrm{NS}}$ & $1034,44^{\mathrm{a}}$ & $-0,615^{\mathrm{b}}$ \\
60 & $1,41^{\mathrm{NS}}$ & $9,49^{\mathrm{a}}$ & $4,43^{\mathrm{b}}$ & $3,47^{\mathrm{a}}$ & $0,78^{\mathrm{NS}}$ & $1034,46^{\mathrm{a}}$ & $-0,615^{\mathrm{b}}$ \\
\hline
\end{tabular}

Médias seguidas de mesma letra não diferem entre si ao nível de 5\% de significância pelo teste Tukey. *NS: Não significativo pela Análise de Variância. Fonte: Elaboração própria das autoras (2018).

No geral, os dados de composição estão de acordo com o que estabelece a legislação para Leite Semidesnatado UHT (Brasil, 1996). Com relação às mudanças nos componentes ao longo dos 60 minutos avaliados, é possível observar que as alterações significativas aconteceram apenas nos teores de Sólidos Não Gordurosos (SNG), Crioscopia, de Lactose estimada e Densidade. Todos os parâmetros anteriormente citados se relacionam direta ou indiretamente à quantidade de lactose presente na amostra: este açúcar compõe a maior porção dos sólidos não gordurosos (cerca de 55\%) e a sua hidrólise em glicose + galactose afeta a quantidade de sólidos dissolvidos no leite (Santos, 2012; Ceroni; Vanin, 2021).

$\mathrm{O}$ teor de massa gorda e proteína não mostraram aumento significativo, apresentando ao final de 60 minutos, acumulando $1,28 \%$ e 3,52\% para enzima A, e 1,41\% e 3,47\% para a enzima B, respectivamente. Esses resultados encontram-se dentro dos padrões previstos para leites semidesnatados, sendo estabelecido $0,6 \%$ a 2,9\% para gordura e no mínimo 2,9\% de proteína (Brasil, 1996). Os dados representados nas Tabelas 1 e 2 demonstram que tanto a enzima lactase comercial quanto o preparado enzimático, que continha lactase, lipase e protease, além de não interferir na concentração de proteína e gordura, não afetou significativamente os teores de minerais, que se mantiveram em uma média geral de $0,78 \%$ e $0,77 \%$, respectivamente.

A variação dos valores obtidos para sólidos não gordurosos foi significativa, atingindo ao final do tempo analisado o teor de 9,60\% para enzima A e 9,49\% para enzima B, valores estes que se encontram dentro dos padrões exigidos pela legislação em relação a leites semidesnatados (mínimo 8,3\%) (Brasil, 1996).

A legislação brasileira não apresenta parâmetro para crioscopia do leite UHT, designando apenas ao leite in natura e pasteurizado (entre $-0,530^{\circ} \mathrm{H} \mathrm{e}-0,555^{\circ} \mathrm{H}$ ) (Brasil, 2017). No entanto, Beloti et al. (2015) sugerem que o ponto de congelamento 
para o leite UHT esteja entre $-0,545^{\circ} \mathrm{H} \mathrm{e}-0,572^{\circ} \mathrm{H}$, faixa que abrange os resultados do presente estudo. Deve-se ressaltar que, considerando que o leite que passa por este tipo de tratamento térmico geralmente recebe adição de estabilizantes, havendo consequente aumento nos sólidos dissolvidos, o que pode ocasionar a redução do ponto de congelamento (Fagnani et al., 2014).

O índice crioscópico do leite é considerado uma propriedade coligativa, ou seja, depende unicamente das substâncias dissolvidas no mesmo, as quais são compostas por lactose e sais em sua maioria, sendo a primeira responsável por 50\% da depressão do ponto de congelamento (Czarnobay, 2017; Lima, 2014). Além disso, a hidrólise da lactose e a dissociação de dois outros açúcares, propicia um aumento no teor de sólidos do leite, o que pode ser observado na Tabela 2 e esse maior número de partículas em solução promove a depressão do ponto de congelamento do leite, afastando-o de zero (Czarnobay, 2017; Fagnani et al., 2014).

Os valores expressos nas Tabelas 1 e 2, indicam que houve alteração significativa no teor de sólidos totais para as amostras adicionadas de lactase e de preparado enzimático contendo lactase. Com relação à densidade do leite, este parâmetro mostrou discreta variação durante o mesmo período de tempo, passando de 1034,56 g/L no tempo 0 para 1034,98 g/L após 1 hora da adição de lactase. Esse discreto aumento provavelmente deveu-se ao desdobramento da lactose nos seus monossacarídeos precursores. O mesmo ocorreu no estudo de Ferreira et al. (2016), em que a densidade antes da hidrólise da lactose era 1032,12 g/L e deslocou-se para 1.032,20 g/L, sendo observado que a reação não teve tanta interferência na relação massa e volume.

E esse aumento da densidade pode em parte explicar a redução do ponto crioscópico das amostras de leite analisadas durante o mesmo período de tempo, dado que o fato da densidade oscilar está essencialmente relacionado a massa e de que a crioscopia varia de acordo com a concentração de íons (Fagnani et al., 2014).

O teor de lactose foi estimado pelo cálculo do grau de redução de lactose, em função do ponto de congelamento, e sólido totais do leite uma vez que a hidrólise da lactose está relacionada com consequente aumento dos açúcares redutores galactose e glicose, interferindo no parâmetro citado. De maneira semelhante, Trevisan (2008) observou em seu estudo que com a utilização de lactase, houve a redução de cerca de 33\% do ponto de congelamento do leite, afirmando que a remoção da lactose provoca a redução do ponto crioscópico. O grau de redução observado no presente estudo, por outro lado, não alcançou tais valores, ficando abaixo de $15 \%$.

Os teores de lactose estimada encontram-se dentro do mínimo estabelecido para leite fluido (mínimo de lactose 4,3\%), padrão utilizado, uma vez que este parâmetro não é abordado na legislação específica para leite UHT (Brasil, 2017). A redução significativa nos valores para a concentração deste açúcar a partir dos 5 minutos indica a atividade enzimática, no entanto os valores encontrados após 60 minutos tanto para a enzima A quanto para a enzima B são superiores ao que se espera de um alimento que sofreu hidrólise enzimática do referido açúcar.

A legislação determina que são considerados produtos zero, isento ou sem lactose, aqueles que prontos para consumo possuem quantidade igual ou inferior a 100 miligramas por 100 gramas ou mililitros do alimento (Brasil, 2017). Os teores de lactose estimados para o produto "pronto para o consumo" conforme o indicado pelo fabricante, ainda tem capacidade de provocar reação clínica moderada a severa em indivíduos portadores da condição em questão.

Os resultados que apresentam a redução do teor de lactose no leite semidesnatado UHT adicionado de enzima lactase comercial (A) e de preparado enzimático contendo lactase (B) ao longo de 60 minutos estão dispostos na Tabela 3. 
Tabela 3 - Redução (\%) da lactose em relação ao teor inicial para leite semidesnatado UHT adicionado de enzima lactase comercial (A) e de preparado enzimático contendo lactase (B) ao longo de 60 minutos.

\begin{tabular}{cccccccc}
\hline & \multicolumn{7}{c}{ Tempo em minutos } \\
& 0 & 5 & 10 & 15 & 20 & 25 & 30 \\
\cline { 2 - 7 } Preparado Enzimático & $0,00^{\mathrm{b}}$ & $-6,17^{\mathrm{ab}}$ & $-8,90^{\mathrm{a}}$ & $-9,08^{\mathrm{a}}$ & $-9,81^{\mathrm{a}}$ & $-9,81^{\mathrm{a}}$ & $-10,35^{\mathrm{a}}$ \\
Lactase Comercial & $0,00^{\mathrm{a}}$ & $0,18^{\mathrm{a}}$ & $-0,18^{\mathrm{a}}$ & $-1,45^{\mathrm{a}}$ & $0,18^{\mathrm{a}}$ & $-1,45^{\mathrm{a}}$ & $0,18^{\mathrm{a}}$ \\
\hline
\end{tabular}

Tempo em minutos (continuação)

\begin{tabular}{ccccccc} 
& 35 & 40 & 45 & 50 & 55 & 60 \\
\cline { 2 - 7 } Preparado Enzimático & $-11,08^{\mathrm{a}}$ & $-11,26^{\mathrm{a}}$ & $-11,62^{\mathrm{a}}$ & $-11,98^{\mathrm{a}}$ & $-12,53^{\mathrm{a}}$ & $-12,53^{\mathrm{a}}$ \\
Lactase Comercial & $-1,63^{\mathrm{a}}$ & $-1,27^{\mathrm{a}}$ & $-1,63^{\mathrm{a}}$ & $-1,82^{\mathrm{a}}$ & $-2,18^{\mathrm{a}}$ & $-3,09^{\mathrm{a}}$
\end{tabular}

Médias seguidas de mesma letra não diferem entre si ao nível de 5\% de significância pelo teste Tukey. Fonte: Elaboração própria das autoras (2018).

Na Figura 2 estão representadas graficamente a redução do teor de lactose do leite quando em contato com as duas enzimas em função do tempo.

Figura 2 - Redução (\%) da lactose em relação ao teor inicial para leite semidesnatado UHT adicionado de enzima lactase comercial (A) e de preparado enzimático contendo lactase (B) ao longo de 60 minutos.

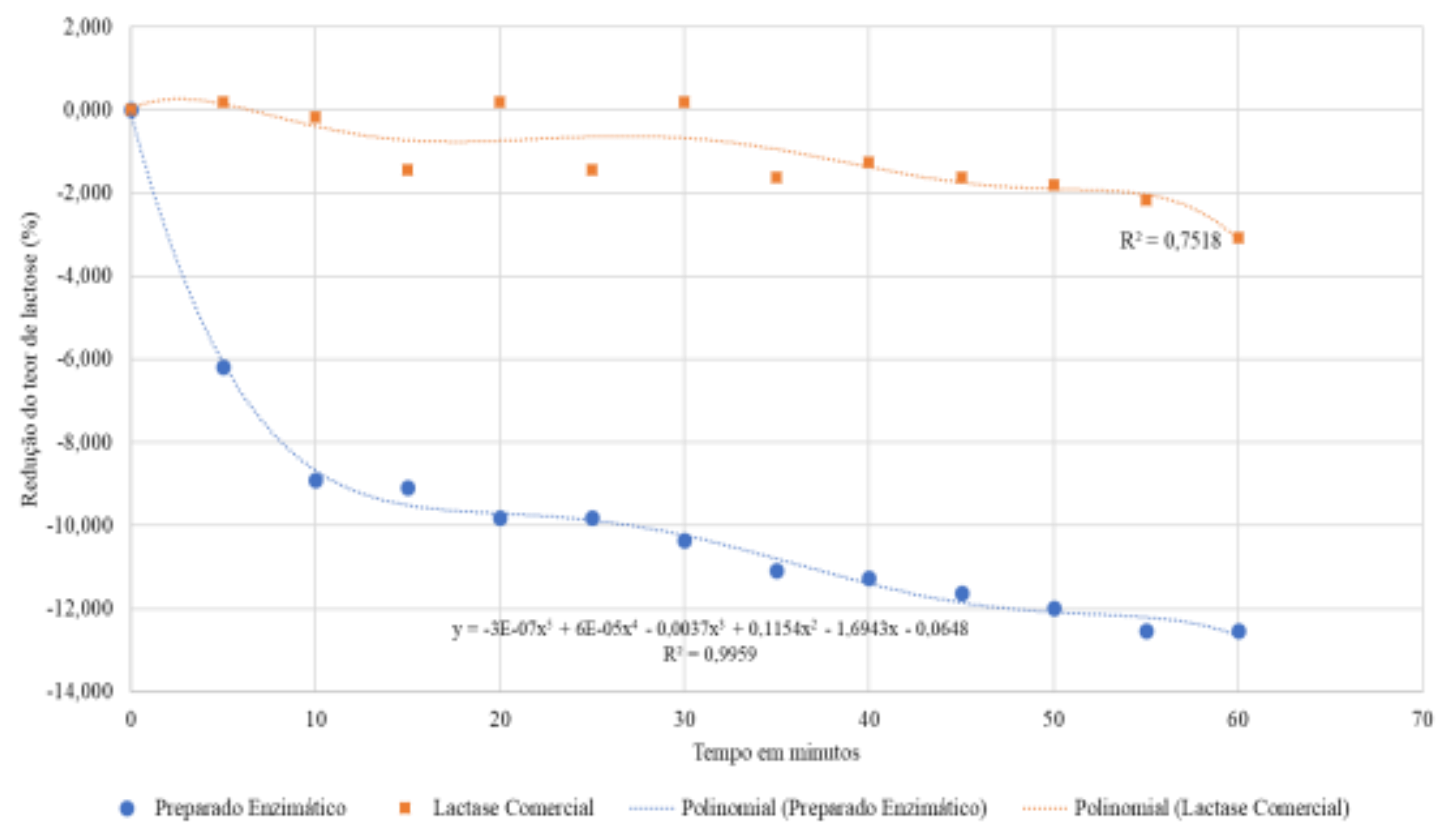

Fonte: Elaboração própria das autoras (2018).

Ao longo dos 60 minutos estudados, o preparado enzimático apresentou maior atividade hidrolítica sobre a lactose, mostrando redução significativa logo nos primeiros 5 minutos. Por outro lado, a lactase comercial não demonstrou redução significativa no teor de lactose em nenhum momento dentro do período estudado.

A redução máxima alcançada para o preparado enzimático foi de 12,53\% aos 60 minutos, valor ainda abaixo do prometido pelo fabricante, que segundo instruções da embalagem, oferece um produto apto para o consumo por indivíduos 
intolerantes a lactose, após 15 minutos de contato da enzima com o leite. Porém os dados da figura 2 ilustram que neste tempo o grau de redução alcançado foi de apenas 9,08\%.

Araújo (2015) também avaliou duas marcas de lactase comercial sob diferentes temperaturas e encontrou melhor atividade enzimática à temperatura de $25^{\circ} \mathrm{C}$, com redução, após 60 minutos, de $41 \%$, resultado maior do que o obtido neste experimento, mas é importante considerar que as marcas avaliadas não foram as mesmas e a metodologia usada para determinar o teor de lactose foi pelo método de Fehling.

Da Silva Campos e colaboradores (2015), em estudo do comportamento da lactase submetida a diversas temperaturas, apresentou hidrólise de lactose de $90 \%$ em temperatura de $20^{\circ} \mathrm{C}$ em 5 horas de experimento.

A análise de regressão permitiu estabelecer um modelo confiável $\left(\mathrm{R}^{2}: 0,9959\right)$ apenas para o preparado enzimático e conforme este modelo matemático, a redução de $90 \%$ do teor de lactose seria obtida após 120 minutos de contato da enzima com o leite, o dobro do tempo estudado e 8 vezes superior ao indicado pelo fabricante.

\section{Conclusão}

O processo de hidrólise enzimática da lactose não exerceu mudança significativa sobre os teores de gordura, proteínas e minerais. No entanto, houveram mudanças significativas nos parâmetros de sólidos não gordurosos, crioscopia, densidade, lactose estimada e redução de lactose, de modo que, a redução de lactose esperada era de no mínimo 90\% para ser considerado deslactosado. Contudo, a máxima redução obtida foi de $12,53 \%$ no tempo de 60 minutos, sendo que a instrução disponibilizada pelos fabricantes das duas marcas de enzimas orienta o consumidor a adicionar o produto ao alimento, homogeneizar por 3 minutos e com 15 minutos consumi-lo.

Observado que o teor de lactose não foi reduzido até a quantidade considerada segura para pessoas com intolerância, torna-se temerária a utilização desses produtos, que se consumidos podem ocasionar reações brandas ou graves nos indivíduos com a patologia.

Ademais, ressaltamos a necessidade da continuidade de estudos visando a hidrólise da lactose do leite, ampliando as possibilidades industriais no desenvolvimento de produtos para indivíduos intolerantes à lactose.

\section{Referências}

Amancio, O. M. S. (2015). A importância do consumo de leite no atual cenário nutricional brasileiro. São Paulo, Sp: Sban, $28,28$.

Araújo, L. L. F. (2015). Avaliação da atividade enzimática da beta-d-galactosidase comercial em diferentes temperaturas. Trabalho de conclusão de curso. Universidade do Estado de Mato Grosso.

Beloti, V., Rios, E. A., Rocha Silva, M., Tamanini, R., Koji Yamada, A., \& Correa da Silva, L. C. (2015). Determination of freezing point standard for UHT milk. Semina: Ciências Agrárias, 36 (5).

Brasil. (1996). Portaria $N^{\circ} 146$ de 07 de março de 1996. Regulamento Técnico de Identidade e Qualidade de Produtos Lácteos (RTIQ). Diário Oficial da União (DOU), 11 de março de 1996.

Brasil. (2014). RDC N 54, de 7 de outubro de 2014 do Regulamento de Inspeção Industrial e Sanitária de Produtos de Origem Animal (RIISPOA). Diário Oficial da União (DOU), 8 de outubro de 2014.

Brasil. (2017). Decreto $n^{\circ}$ 9.013, de 29 de março de 2017 do Regulamento de Inspeção Industrial e Sanitária de Produtos de Origem Animal (RIISPOA). Diário Oficial da União (DOU), 30 de março de 2017.

Brasil. (2017). Resolução da Diretoria Colegiada - RDC 136, 09 de Fevereiro de 2017. Agência Nacional de Vigilância Sanitária (ANVISA). Diário Oficial da União (DOU), 9 de fevereiro de 2017.

Ceroni, F. L., \& Vanin, A. B. (2021). Estudo cinético das enzimas hidrolases quimosina e lactase em leite bovino. Brazilian Journal of Development, 7(2), 19040-19053.

Cunha, L. R. D., Soares, N. D. F. F., Assis, F. C. C., Melo, N. R. D., Pereira, A. F., \& Silva, C. B. D. (2007). Desenvolvimento e avaliação de embalagem ativa com incorporação de lactase. Food Science and Technology, 27, 23-26. 
Research, Society and Development, v. 10, n. 14, e262101421898, 2021

(CC BY 4.0) | ISSN 2525-3409 | DOI: http://dx.doi.org/10.33448/rsd-v10i14.21898

Czarnobay, M., Brião, V. B., Rodrigues, V. M., Milani, A., \& Castoldi, V. (2017). Cinética de hidrólise de lactose em leite de ovelha e leite de vaca. Revista CIATEC-UPF. 9(1).

Da Silva Campos, T. C. Á., D’Almeida, W. K., Alegro, L. C. A., Roig, S. M., \& Suguimoto, H. H. (2015). Utilização da $\beta$-galactosidase na Hidrólise da Lactose do Leite em Baixa Temperatura. Journal of Health Sciences, 11 (4).

Dos Santos, A. C., da Silva Junior, R. C., Olivo, P. M., Osmari, M. P., \& Istvan, F. (2019). Adição de lactase na caracterização físico-química, microbiológica e sensorial de iogurte de leite de cabra.

Fagnani, R., Carraro, P. E., Battaglini, A. P. P., \& De Araújo, J. P. A. (2014). Alterações na densidade e crioscopia do leite pela adição de diferentes concentrações de citrato e fortificante. Revista Caatinga, 27 (4), 208-15.

Ferreira, A. T. D., Levandoski, D. M. Z., \& Favoreto, V. Z. (2016). Análises físico-químicas em amostras de leites semidesnatados: com lactose e sem lactose. Trabalho de Conclusão de Curso. Universidade Tecnológica Federal do Paraná.

Klein, M. P., Jong, E. V. D., \& Révillion, J. P. P. (2010). Utilização da $\beta$-galactosidase para prevenção da cristalização em doce de leite. Ciência e Agrotecnologia, 34, 1530-1535.

Lima, L. S. (2014). Propriedades coligativas. Revista de Ciência Elementar, 2(1).

Prozyn. (2007). Prozyn Lactase. São Paulo. 5p. Informação técnica.

Santos, M. V. (2012). Ponto de congelamento do leite: variações x fraldes.

Trevisan, A. P. (2008). Influência de diferentes concentrações de enzimas lactase e temperaturas sobre a hidrólise da lactose em leite pasteurizado. Dissertação de Mestrado - Universidade Federal de Santa Maria. Santa Maria, p. 60.

Venturoso, R. C., De Almeida, K. E., Rodrigues, A. M., Damin, M. R., \& De Oliveira, M. N. (2007). Determinação da composição físico-química de produtos lácteos: estudo exploratório de comparação dos resultados obtidos por metodologia oficial e por ultra-som. Revista Brasileira de Ciências Farmacêuticas, 43 (4), 607-13. 